\title{
Hepatoprotective Effects of a Novel Trihoney against Nonalcoholic Fatty Liver Disease: A Comparative Study with Atorvastatin
}

\author{
Hamad Abdulsalam Hamad Alfarisi $\left(\mathbb{D},{ }^{1}\right.$ Muhammad Bin Ibrahim $\mathbb{D}^{1}$, \\ Zenab B. Hamad Mohamed, ${ }^{1}$ Nuraniza Azahari, ${ }^{1}$ Asmah Hanim Bt. Hamdan, \\ and Che Anuar Che Mohamad ${ }^{3}$ \\ ${ }^{1}$ Department of Nutrition Sciences, Kulliyyah of Allied Health Sciences, International Islamic University Malaysia, \\ Kuantan 25200, Pahang, Malaysia \\ ${ }^{2}$ Department of Pathology and Laboratory Medicine, Kulliyyah of Medicine, International Islamic University Malaysia, \\ Kuantan.25200, Pahang, Malaysia \\ ${ }^{3}$ Department of Basic Medical Sciences, Kulliyyah of Pharmacy, International Islamic University Malaysia, Kuantan.25200, \\ Pahang, Malaysia
}

Correspondence should be addressed to Muhammad Bin Ibrahim; abumaisarah@iium.edu.my

Received 23 September 2019; Revised 7 September 2020; Accepted 23 September 2020; Published 9 October 2020

Academic Editor: Davide Firinu

Copyright ( $\odot 2020$ Hamad Abdulsalam Hamad Alfarisi et al. This is an open access article distributed under the Creative Commons Attribution License, which permits unrestricted use, distribution, and reproduction in any medium, provided the original work is properly cited.

Nonalcoholic fatty liver disease (NAFLD) is the most prevalent chronic liver disorder worldwide with no curative therapy. The aim of this study was to investigate the hepatoprotective effects of a novel Trihoney against biochemical and histological manifestations of NAFLD in hypercholesterolemic rabbits. Methodology. Forty-eight male New Zealand white (NZW) rabbits were grouped into normal diet $(\mathrm{C})$, normal diet with $0.6 \mathrm{~g} / \mathrm{kg} /$ day of Trihoney $(\mathrm{C}+\mathrm{H}), 1 \%$ cholesterol diet $(\mathrm{HCD}), 1 \%$ cholesterol diet with $0.3 \mathrm{~g} / \mathrm{kg} /$ day of Trihoney $\left(\mathrm{HCD}+\mathrm{H}_{1}\right), 1 \%$ cholesterol diet with $0.6 \mathrm{~g} / \mathrm{kg} /$ day of Trihoney $\left(\mathrm{HCD}+\mathrm{H}_{2}\right)$, and $1 \%$ cholesterol diet with $2 \mathrm{mg} / \mathrm{kg} /$ day of atorvastatin (HCD + At.). Animals were sacrificed after 12 weeks of treatment. Serum lipids and liver function test (LFT) were measured prior to and at the endpoint of the experiment for total cholesterol (TC), low-density lipoprotein (LDL-c), alanine aminotransferase (ALT), aspartate aminotransferase (AST), alkaline phosphatase (ALP), gamma-glutamyl transferase (GGT), and total bilirubin (T. Bil.). Liver was processed for histopathology study. Liver homogenate was analysed for oxidative stress parameters: superoxide dismutase (SOD), glutathione peroxidase (GPx), and malondialdehyde (MDA). Results. Lipid analysis approved the induction of hypercholesterolemia. A significant elevation $(p<0.01)$ of serum AST and ALT levels showed by the HCD group was compared to $\mathrm{C}$ and $\mathrm{C}+\mathrm{H}$ groups. Trihoney exhibited a significant reduction $(p<0.001)$ of AST and ALT compared to the HCD group. Likewise, AST and ALT reduced significantly in the HCD + At. group $(p<0.001)$. Trihoney supplementation induced significant $(p<0.05)$ enhancement of SOD and GPx activities. Atorvastatin treatment was associated with significant $(p<0.05)$ reduction of SOD and GPx activities in the liver. Trihoney and atorvastatin showed marked $(p<0.001)$ reduction of hepatic lipid peroxidation. Trihoney showed histological protection against progression of NAFLD to nonalcoholic steatohepatitis (NASH). Atorvastatin exhibited no beneficial impact on hepatic architecture. Conclusion. Trihoney was able to maintain normal liver function and showed hepatoprotection against progression of NAFLD to NASH probably through hypocholesterolaemic and antioxidant functions.

\section{Introduction}

Nonalcoholic fatty liver disease is the most prevalent chronic liver disorder worldwide with no curative therapy [1]. Nonalcoholic fatty liver disease constitutes a spectrum of histological changes in the liver (due to fatty infiltration) ranging from simple steatosis to NASH (aggressive form) [2]. Differentiation between NAFLD and NASH can only be made on histological basis [3]. The global prevalence of NAFLD is $25.24 \%$ with highest prevalence in the Middle East 
and South America and lowest in Africa [4]. It is estimated that the prevalence of diagnosed cases of NASH will approach 18 million by 2027 in the USA, Japan, England, France, Germany, Italy, and Spain [1]. In Asia, the population prevalence of NAFLD is $25 \%$, which is almost like that of Western countries, and this trend was attributed to the modern sedentary lifestyle and dietary habits [5]. The recently accepted theory explaining pathogenesis of NAFLD is the "multiple hit" theory which proposed multiple insults act together in genetically predisposed individual to induce NAFLD, and the multiple hits include insulin resistance, hormones secreted from the adipose tissue, nutritional factors, gut microbiota, and genetic and epigenetic factors [6]. Oxidative stress, lipid peroxidation, and inflammation are the underlying operating mechanisms for initiation and progression of NAFLD [6-9]. Despite its worldwide prevalence and clinical burden, to date, NAFLD has no curative pharmacological treatment [10]. Healthy lifestyle with correct dietary habits definitely maintains healthy status and protects against NAFLD [11]. Honey has been used as food and medicine by ancient and modern world and by all traditions and civilisations [12]. Natural honey has been reported to possess hepatoprotective properties through its unique constituents [13], antioxidant [14], and anti-inflammatory [15] functions. The aim of this study was to investigate the hepatoprotective effect of a novel Trihoney against biochemical and histological manifestations of NAFLD in hypercholesterolemic rabbits. Trihoney is a combination of Trigona, mellifera, and dorsata honey, the combination ratio was 45,15 , and 10 of the mentioned honey, respectively, and it was determined by Design Expert Version 6.0 software and response surface methodology (RSM) looking for a combination formula having the maximum total phenolic content (TPC) [16]. Trigona and dorsata honey are local Malaysian honey with proven high antioxidant capacities. Trigona has a sour taste because of that people may not tolerate it. However, it has a very high phenolic content and hence its powerful antioxidant function [17]. Dorsata honey is also proven to have a profound antioxidant function [18]. Because oxidative stress is documented as an underlying pathogenic mechanism in many diseases such as NAFLD/NASH, the aim was to formulate a combination from those potent antioxidant honey and making them tastily tolerable by adding to them mellifera honey. The TPC of Trihoney $[(0.307 \pm 0.004) \mathrm{mg}$ GAE/g Trihoney] was superior on that of each individual honey. Moreover, Trihoney had high concentrations of phenolic compounds such as quercetin, kaempferol, rutin, catechin, maleic acid, caffeic acid, cinnamic acid, coumaric acid, gallic acid, p-hydroxybenzoic acid, salicylic acid, sinapic acid, and vanillic acid, in addition to high antioxidant properties such as ferric reducing ability of plasma analysis (FRAP) and DPPH free radical scavenging activity analysis [16]. The current study represents the first in vivo application of this combination which is suggested to provide synergistic effects with regard to the protective functions against NAFLD and NASH through antioxidant [19] and anti-inflammatory effects [16].

\section{Materials and Methods}

2.1. Chemicals and Reagents. Pure cholesterol powder is obtained from Nacalai-Tesque (Kyoto, Japan). Cholesterolfree extra virgin coconut oil is bought from Philippines. Masson's Trichrome (MT) stain kit is from Clin-Tech (UK). Other solvents, chemicals, and haematoxylin and eosin (H\&E) stain were supplied by Sigma-Aldrich (USA) and Leica Biosystems (Germany).

2.2. Trihoney and Atorvastatin. Trihoney is a product made in Department of Nutrition Sciences laboratories of Kulliyyah of Allied Health Sciences, International Islamic University Malaysia (IIUM). Trihoney is a combination of three types of natural honey: Trigona, mellifera, and dorsata, at a ratio of $45 \%, 15 \%$, and $10 \%$, respectively [16]. Trihoney was administered to the respective animal groups by oral route. Two doses have been used $(0.3 \mathrm{~g} / \mathrm{kg} /$ day and $0.6 \mathrm{~g} / \mathrm{kg} /$ day). These rabbit equivalent doses have been calculated based on the human daily recommended dose of honey which ranges from 0.1 to $0.2 \mathrm{~g} / \mathrm{kg}[20,21]$. Using ReaganShaw et al. [22] principle, animal equivalent dose is calculated according to the following equation: (human equivalent dose $\times$ human $\mathrm{K}_{m}$ factor = animal equivalent dose $\times$ animal $K_{m}$ factor), with the adult human $K_{m}$ factor being 37 and the rabbit $\mathrm{K}_{m}$ factor being $12 . \mathrm{K}_{m}$ factor is a constant calculated based on normalisation of body surface area for accurate translation of drug doses between mammalian species [22]. Atorvastatin $40 \mathrm{mg}$ film-coated tablets (Prague-Czech) were crushed into fine powder, reconstituted in $1 \mathrm{~mL}$ of distilled water, and given by oral gavage using clean syringe [23-25], at a dose of $2 \mathrm{mg} / \mathrm{kg}$ body weight $[23,26]$.

2.3. Preparation of $1 \%$ Cholesterol Diet. Preparation of $1 \%$ cholesterol diet was performed according to Alfarisi et al. [19] as follows: $40 \mathrm{~g}$ of pure cholesterol powder (NacalaiTesque, Kyoto, Japan) was emulsified in $80 \mathrm{~mL}(=80 \mathrm{~g})$ of cholesterol-free extra virgin coconut oil (product of Philippines). The cholesterol emulsion evenly poured over $3,880 \mathrm{~g}$ of standard rabbit pellets (Perternakan Hong Lee Sdn. Bhd, Malaysia). The prepared food ( $1 \%$ cholesterol and $2 \%$ coconut oil rabbit pellet) was packed in zipped bags and kept at temperature of $20-22^{\circ} \mathrm{C}$ for use.

2.4. Animal. Forty-eight NZW rabbits of male gender were purchased from certified experimental animal supplier (A Sapphire Enterprise, Seri Kembangan, Selangor, Malaysia). Animal weight ranged from 2 to $2.5 \mathrm{~kg}$, and animals' age was 20 weeks. Animals were randomly housed in stainless-steel cages designed for rabbits as a single rabbit per cage with free access to water and standard rabbits' pellet, in addition to the standard animal care housing condition of 12 hours dark/light cycle, temperature 15-21, and humidity $45-65 \%$. The procedure of animal handling was conducted in accordance with the guidelines of Malaysian Code of Practice 
for the Care and Use of Animals for Scientific Purposes (AEPC) [27], and the protocol of this experiment was approved by the Institutional Animal Care and Use Committee of International Islamic University Malaysia (IACUC-IIUM) with ID approval (IIUM/IACUC-Approval/2017 (19)).

2.5. Experimental Study. Forty-eight male NZW rabbits were grouped into the following 6 groups: normal diet $(\mathrm{C})$, normal diet with Trihoney dose of $0.6 \mathrm{~g} / \mathrm{kg} /$ day $(\mathrm{C}+\mathrm{H}), 1 \%$ cholesterol diet (HCD), $1 \%$ cholesterol diet with $0.3 \mathrm{~g} / \mathrm{kg} /$ day of Trihoney $\left(\mathrm{HCD}+\mathrm{H}_{1}\right), 1 \%$ cholesterol diet with $0.6 \mathrm{~g} / \mathrm{kg} /$ day of Trihoney $\left(\mathrm{HCD}+\mathrm{H}_{2}\right)$, and $1 \%$ cholesterol diet with $2 \mathrm{mg} / \mathrm{kg} /$ day of atorvastatin (HCD + At.). At the end of 12 weeks, animals were sacrificed at the animal surgical laboratory of central research and animal facility, International Islamic University Malaysia (CREAM)-IIUM. Induction of general anaesthesia was done by intramuscular injection of a combination of ketamine and xylazine [28] at doses of $50 \mathrm{mg} / \mathrm{kg}$ and $10 \mathrm{mg} / \mathrm{kg}$, respectively [29]. Laparotomy and sternotomy were performed for full exposure of liver [30], and then through left ventricular approach, systemic perfusion was secured by infusion of ice-cold normal saline and euthanasia was achieved by exsanguination of blood through opened right atrium $[31,32]$. Portal vein was cannulated for further hepatic perfusion with ice-cold $0.9 \% \mathrm{NaCl}$ for achievement of full hepatic tissue clearance [33]. Liver was then released, immediately weighed, and reexamined in a container filled with iced-cold phosphate buffer saline (PBS). Liver tissue was cut into 3 pieces of $6 \mathrm{~g}$ each for later homogenate study [33] and immediately stored at $-80^{\circ} \mathrm{C}$ (Haier Ult Freezer, China) until homogenisation [34]. Piece of right lobe from each animal was cut to ensure optimisation and consistency [35] and then immediately fixed in 10\% neutral buffer formalin (NBF) [36,37] for histopathology study.

2.6. Blood Samples and Serum Preparation. Blood was collected from the animals twice, one time on day zero for baseline investigation and for verification of any physiological differences between animals and the second time at the endpoint of the experiment $[23,28]$. Blood was withdrawn from central ear artery [29], collected in plain tubes, allowed to clot at room temperature for 40 minutes [38], and then centrifuged (Centrifuge Universal 320R Hettich, Germany) at 4 by speed of $3500 \mathrm{rpm}$, for 15 minutes [39, 40]. Serum samples were immediately sent for biochemical analysis.

2.7. Liver Homogenate Preparation. Liver tissue was retrieved from $-80^{\circ} \mathrm{C}$ freezer and defrosted. Using bullet blender homogeniser, liver tissue was homogenised to a ratio of $10 \%(\mathrm{w} / \mathrm{v})$ [41] as follows: $100 \mathrm{mg}$ tissue in $900 \mu \mathrm{L}$ PBS (Sigma-Aldrich, USA) [42] supplemented with protease cocktail inhibitor (Nacalai-Tesque, Japan) [43]. Homogenised tissue was centrifuged (ThermoFisher Scientific, Germany) for 15 minutes at $10,000 \mathrm{rpm}$ at $4^{\circ} \mathrm{C}[42,43]$. The supernatant was stored immediately at $-80^{\circ} \mathrm{C}$ for later assay
[44]. Protein concentration in tissue homogenate was measured according to Coomassie (Bradford) protein assay method [43] using Coomassie Brilliant Blue (CBB) solution (Ready to Use) (Nacalai-Tesque, Japan).

2.8. Serum Biochemical Analysis. Serum samples for TC, ALT, AST, ALP, GGT, and T. Bil. were immediately analysed by automated analysis machine (Au480 Auto Analyser-Beckman Coulter, Inc.). Serum LDL-c was calculated according to Friedewald equation [45]: LDL- $c=$ TC $-\mathrm{HDL}-c-(\mathrm{TG} / 5)$ $\mathrm{mmol} / \mathrm{L}$.

\subsection{Antioxidant Study}

2.9.1. Lipid Peroxidation Assay in Liver Homogenate. Concentration of MDA in liver homogenate was determined quantitively using OxiSelect MDA Adduct competitive enzyme-linked immunosorbent assay (ELISA) according to the manufacturer's protocol (Cell Biolabs, USA).

2.9.2. Antioxidant Enzyme Assay in Liver Homogenate. Superoxide dismutase enzyme activity was assayed using OxiSelect $^{\mathrm{TM}}$ Superoxide Dismutase Activity Assay Kit (Cell Biolabs, USA). Enzyme activity as function of optical density (OD) was expressed as units/ $\mu \mathrm{L}$ and calculated as percentage (\%). Activity of GPx was assayed using GPx assay kit (Abnova, Taiwan). The principle of GPx assay was based on the decrease in NADPH (measured at $340 \mathrm{~nm}$ ) which is proportionate to GPx activity. Activity of GPx in the homogenate was expressed in $\mathrm{mU} / \mathrm{mg}$ tissue protein.

2.10. Histopathological Study Using HeE and MT Staining. Liver tissue was fixed in $10 \% \mathrm{NBF}$ for at least 72 hours and then was processed in automated tissue processor (Leica Microsystem, Germany), clarified in xylene, and embedded by embedding Centre (Tissue-Tek ${ }^{\circledR} \mathrm{Tec}^{\mathrm{TM}}$, Germany). Trimming and sectioning of $3 \mu \mathrm{m}$ thick ribbon were performed using a semiauto rotator microtome (Leica Microsystem, Germany) and mounted onto frosted glass microscope slides. Haematoxylin and eosin [46] and MT staining [47] were employed. Staging and grading of histopathological findings were performed according to Brunt et al. [48] grading and staging system of NASH.

2.11. Statistical Analysis. Statistical Package for Social Sciences (SPSS version 21 Chicago, Illinois, USA) software was used for data processing. Data were expressed as mean $(M)$ and standard deviation (SD) and analysed by one-way analysis of variance (ANOVA). One-way ANOVA followed by the post hoc test was used for determination of any significant differences between means of two or more independent groups. Statistical significance was considered at $p<0.05$. Correlations were investigated using Pearson's correlation coefficients $(r)$. 


\section{Results}

3.1. Effects of Trihoney and 1\% Cholesterol Diet on Animal's Food Intake. Results of animal's food intake are displayed in Table 1. Continuous feeding and treating NZW rabbits with the designed regimen showed no significant $(p>0.05)$ difference between all experimental groups prior to induction phase (week 0) and after treatment phase (week 12). However, comparison by repeated measurements of animal's food intake pre- and posttreatment (Figure 1) showed a significant reduction $(p<0.05)$ in animals' food intake at the end of the treatment duration when compared to pretreatment starting point.

3.2. Trihoney Normalises Liver Function in NAFLD. Definitely, there was no difference $(p>0.05)$ in liver function parameters between all experimental groups before phase of induction (Table 2). While after 12 weeks of treatment (Table 2), the HCD group had a significant elevation $(p<0.001)$ of serum AST when compared to $\mathrm{C}$ and $\mathrm{C}+\mathrm{H}$ groups and a significant elevation $(p<0.01)$ of serum ALT in comparison to the $\mathrm{C}$ group. More significant elevation $(p<0.001)$ of serum ALT level was seen between the $\mathrm{HCD}$ group and $\mathrm{C}+\mathrm{H}$ group. Trihoney-treated groups showed significant reduction $(p<0.001)$ of both liver enzymes AST and ALT when compared to the HCD group. Likewise, the atorvastatin-treated group exhibited significant $(p<0.001)$ lower serum AST and ALT compared to the HCD group. Serum transaminases in the atherogenic-treated groups were comparable to the controls. Serum T. Bil. and GGT were lower in Trihoney-treated groups in comparison to HCD and HCD + At. groups despite no statistical significance.

\subsection{Correlation between Liver Parameters and Serum} Cholesterol. A significant $(p<0.05)$ positive correlation was found between serum AST, TC, and LDL-c levels. Moreover, T. Bil. had significant $(p<0.01)$ positive correlation with serum TC level and significant $(p<0.05)$ correlation with LDL-c (Table 3).

\subsection{Trihoney Enhances Antioxidant Enzymes in NAFLD.} There were a very significant $(p<0.001)$ reduction of SOD and GPx $(p<0.05)$ activities in the HCD group compared to the control group (Table 4). Contrarily, treatment group $\mathrm{HCD}+\mathrm{H}_{1}$ exhibited the highest $(p<0.001)$ SOD activity among all atherogenic groups; moreover, this group showed the highest GPx activity despite no statistical significance difference compared to $\mathrm{HCD}$ and $\mathrm{HCD}+\mathrm{H}_{2}$ groups. Activity of GPx was significantly $(p<0.05)$ enhanced in the $\mathrm{HCD}+\mathrm{H}_{1}$ group compared to the $\mathrm{HCD}+$ At. group. Group $\mathrm{HCD}+\mathrm{H}_{2}$ had SOD and GPx activities higher than the HCD and $\mathrm{HCD}+$ At. groups though no statistical significance difference. On the contrary, the atherogenic group received atorvastatin $\mathrm{HCD}+$ At. showed low SOD and GPx activities in liver homogenate when compared to all untreated and treated groups.
TABLE 1: Effect of $1 \%$ cholesterol diet and Trihoney on animal's food intake.

\begin{tabular}{lcc}
\hline Groups & Food intake $(\mathrm{g})$, week 0 & Food intake $(\mathrm{g})$, week 12 \\
\hline $\mathrm{C}$ & $112.86 \pm 15.69^{\mathrm{a}}$ & $106.86 \pm 39.04^{\mathrm{a}}$ \\
$\mathrm{C}+\mathrm{H}$ & $118.38 \pm 33.34^{\mathrm{a}}$ & $89.50 \pm 55.68^{\mathrm{a}}$ \\
$\mathrm{HCD}$ & $100.87 \pm 37.21^{\mathrm{a}}$ & $74.50 \pm 30.92^{\mathrm{a}}$ \\
$\mathrm{HCD}+\mathrm{H}_{1}$ & $81.87 \pm 35.93^{\mathrm{a}}$ & $80.00 \pm 42.50^{\mathrm{a}}$ \\
$\mathrm{HCD}+\mathrm{H}_{2}$ & $99.50 \pm 45.11^{\mathrm{a}}$ & $80.25 \pm 31.59^{\mathrm{a}}$ \\
$\mathrm{HCD}+\mathrm{At}$ & $85.25 \pm 36.73^{\mathrm{a}}$ & $80.28 \pm 26.69^{\mathrm{a}}$ \\
\hline
\end{tabular}

Values are mean \pm standard deviation (SD) of the mean. The results of all experiment groups were analysed using one-way analysis of variance (ANOVA), followed by the Tukey HSD post hoc test. Mean difference is considered significant at $p<0.05$. ${ }^{a}$ Values not sharing a common superscript letter within the same column differ significantly at $p<0.05$. $\mathrm{C}=$ control and $\mathrm{C}+\mathrm{H}=$ control group received a honey dose of $0.6 \mathrm{~g} / \mathrm{kg}$. $\mathrm{HCD}=$ high cholesterol diet; $\mathrm{HCD}+\mathrm{H}_{1}$ and $\mathrm{HCD}+\mathrm{H}_{2}=$ atherogenic groups received a honey dose of 0.3 and $0.6 \mathrm{~g} / \mathrm{kg}$, respectively; $\mathrm{HCD}+\mathrm{At}=$ atherogenic group received atorvastatin dose of $2 \mathrm{mg} / \mathrm{kg}$.

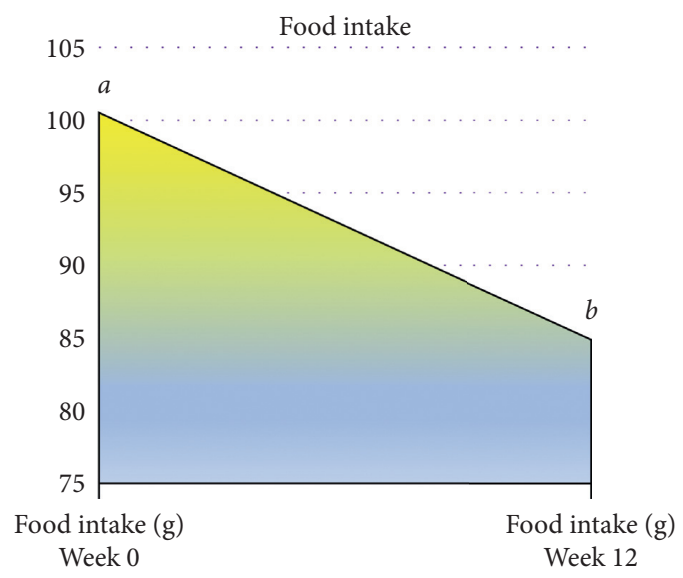

FIGURE 1: Follow-up of animal's food intake during the experiment. Values are means of 8 rabbits per group. The results of all experiment groups were analysed using repeated measure analysis of variance (repeated measure ANOVA), with multiple comparisons done using the Bonferroni test. Mean difference is considered significant at $p<0.05 .{ }^{\mathrm{a}, \mathrm{b}}$ Values differ significantly at $p<0.05$.

3.5. Trihoney Ameliorates Hepatic Lipid Peroxidation. High cholesterol diet induced significant $(p<0.001)$ elevation of MDA concentration in liver compared to the control groups (Table 4). Trihoney- and atorvastatin-treated groups showed significant $(p<0.001)$ reduction of MDA concentration in the liver compared to the HCD group. Both $\mathrm{HCD}+\mathrm{H}_{2}$ and $\mathrm{HCD}+$ At. had liver MDA concentration comparable to that of the control groups.

\subsection{Trihoney Exhibited Histological Protective Effects against Progression of NAFLD to NASH}

3.6.1. Macroscopic Examination. Macroscopically (Figure 2), control groups $\mathrm{C}$ and $\mathrm{C}+\mathrm{H}$ showed similar gross morphological features comprised shiny deep maroon colour, smooth surface, soft consistency, and deep maroon cut surface. The liver of the HCD group had yellowish discolouration, smooth surface, hard consistency, and 


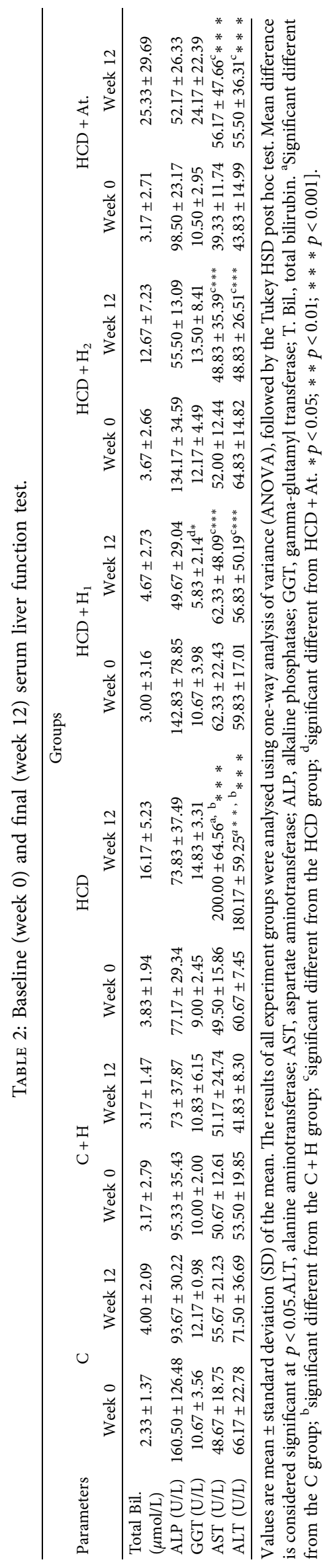


TABLE 3: Correlation $(r)$ between serum liver parameters and lipid profile at week 12.

\begin{tabular}{lcc}
\hline & TC $(\mathrm{mmol} / \mathrm{L})$ & LDL-c $(\mathrm{mmol} / \mathrm{L})$ \\
\hline AST $(\mathrm{U} / \mathrm{L})$ & $r=0.350^{*}$ & $r=0.398^{*}$ \\
T. Bil. $(\mu \mathrm{mol} / \mathrm{L})$ & $r=0.437^{* *}$ & $r=0.410^{*}$ \\
\hline
\end{tabular}

Values are the Pearson correlation coefficient $(r)$ between serum level of liver biochemical parameters and lipid profile at week 12. $r$ is the Pearson correlation coefficient. ${ }^{*} p<0.05 ;{ }^{* *} p<0.01$ Sig. (2-tailed).

TABLE 4: Effect of Trihoney on activities of SOD and GPx and on MDA concentration in liver homogenate of NAFLD at week 12.

\begin{tabular}{lccc}
\hline Group & SOD activity $(\%)$ & GPx activity $(\mathrm{mU} / \mathrm{mg}$ protein) & MDA $(\mu \mathrm{g} / \mathrm{mg}$ protein) \\
\hline $\mathrm{C}$ & $61.43 \pm 2.69$ & $109.88 \pm 40.44$ & $0.00 \pm 0.00$ \\
$\mathrm{C}+\mathrm{H}$ & $46.89 \pm 2.44$ & $90.97 \pm 37.26$ & $0.03 \pm 0.01$ \\
HCD & $27.98 \pm 7.05^{\mathrm{a}, \mathrm{b} * * *}$ & $49.98 \pm 36.40^{\mathrm{a} *}$ & $0.98 \pm 0.17^{\mathrm{a}, \mathrm{b} * * *}$ \\
$\mathrm{HCD}+\mathrm{H}_{1}$ & $50.95 \pm 5.15^{\mathrm{a}, \mathrm{c} * * *}$ & $95.68 \pm 13.77$ & $0.31 \pm 0.12^{\mathrm{a}, \mathrm{b} * *, \mathrm{c} * * *}$ \\
HCD + H & $29.89 \pm 10.62^{\mathrm{a} * * *, \mathrm{~b} * *, \mathrm{~d} * * *}$ & $72.45 \pm 22.16$ & $0.14 \pm 0.04^{\mathrm{c} * * *, \mathrm{~d} *}$ \\
HCD + At. & $26.43 \pm 5.49^{\mathrm{a}, \mathrm{b}, \mathrm{d} * * *}$ & $37.45 \pm 33.66^{\mathrm{a}, \mathrm{b} *, \mathrm{~d} *}$ & $0.08 \pm 0.13^{\mathrm{c} * * *, \mathrm{~d} * *}$ \\
\hline
\end{tabular}

Values are mean \pm standard deviation (SD) of the mean. The results of all experiment groups were analysed using one-way analysis of variance (ANOVA), followed by LSD post hoc test. Mean difference is considered significant at $p<0.05$. ${ }^{\mathrm{a}}$ Significant different from the $\mathrm{C}$ group; ${ }^{\mathrm{b}}$ significant different from the $\mathrm{C}+\mathrm{H}$ group; ${ }^{\mathrm{c}}$ significant different from the HCD group; ${ }^{\mathrm{d}}$ significant different from the $\mathrm{HCD}+\mathrm{H}_{1}$ group. ${ }^{*} p<0.05 ;{ }^{* *} p<0.01 ;{ }^{* * *} p<0.001$.
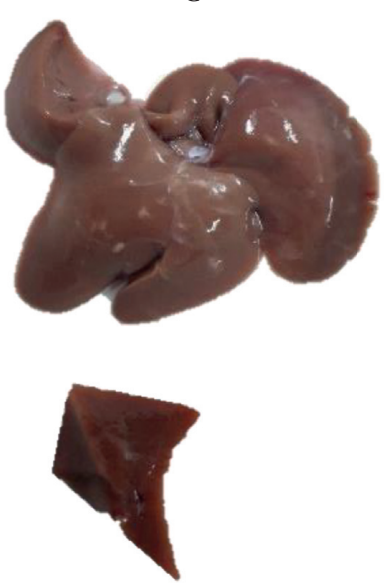

$\mathrm{HCD}+\mathrm{H}_{1}$
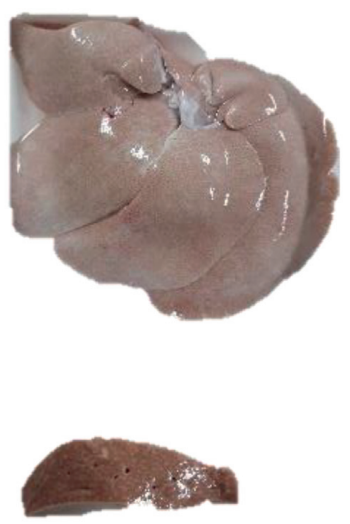

$\mathrm{C}+\mathrm{H}$
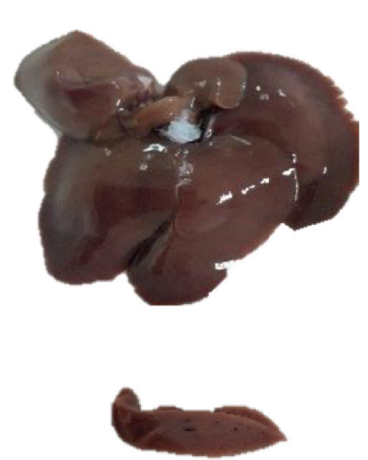

$\mathrm{HCD}+\mathrm{H}_{2}$
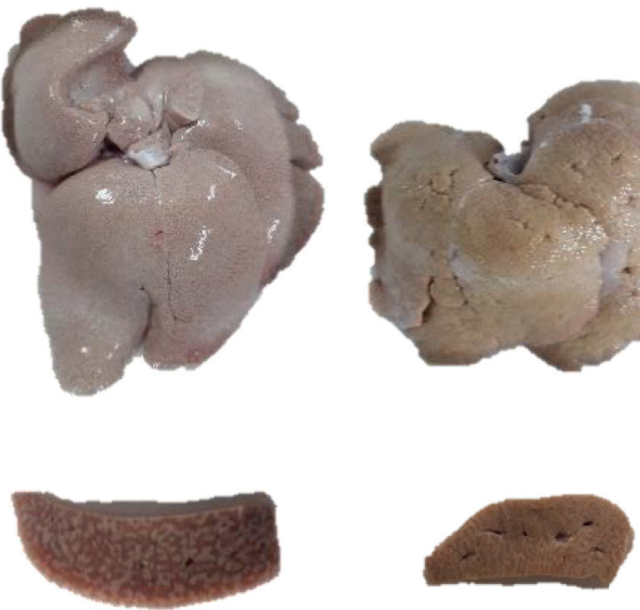

Figure 2: Macroscopic features and cut surface of a representative liver from each experimental group. 
yellowish-brown cut surface. Trihoney-treated groups exhibited pale to yellow surface colour, soft consistency, and brown cut surface. Atorvastatin-treated group showed rough yellow-coloured surface, hard consistency, and yellowishbrown cut surface.

3.6.2. Microscopic Study. Microscopically (Figure 3), H\&E staining of liver tissue of $\mathrm{C}$ and $\mathrm{C}+\mathrm{H}$ groups showed normal hepatic tissue architecture. Staining by MT showed normal distribution of collagen fibres around the hepatic lobules and around the portal triads. Contrary, H\&E staining of liver tissue of the HCD group demonstrated histological picture of NASH composed of macro- and microvesicular steatosis, ballooning, hepatic lobular inflammation with inflammatory infiltration by lymphocytes, plasma cells, occasionally neutrophils, and very prominent Mallory-Denk bodies. Masson's trichrome staining of this group showed fibrotic histopathological changes involved in acinar zones 1,2, and 3 , indicating advanced course of the disease, in addition to extensive hepatic fibrosis in the form of perisinusoidal, pericellular fibrosis giving picture of "chicken wire" which is typical of NASH. Moreover, MT staining highlighted deposition of collagen in periportal areas and showed bridging of fibrosis. Collectively, these histopathological findings are consistent with grade-2 (moderate) $\mathrm{NASH}$ and fibrotic stage-3. On the contrary, H\&E staining of liver tissue of the Trihoney-treated groups showed evidence of NAFLD and focal mild grade-1 NASH (macro- and microvesicular steatosis, hepatic lobular inflammation, inflammatory cell infiltrates, no Mallory-Denk bodies, and no hepatocellular ballooning). Masson's trichrome staining of these groups showed histopathological changes involved in acinar zone 3 in the form of very minimal perisinusoidal fibrosis indicating early phase of the NAFLD fibrotic stage-1. Haematoxylin and eosin staining of HCD + At. liver tissue and MT staining showed histopathological grade-2 (moderate) $\mathrm{NASH}$ and fibrotic stage- 3 .

\section{Discussion}

Normal range of food intake in rabbits varies and is determined by factors such as animal's age, activity, and other environmental factors [49]. In this experiment, animals were allowed to feed on $160 \mathrm{~g} /$ day throughout the experimental period [49]. In this study, weekly food intake measurements showed gradual reduction in food intake by all groups of animals and throughout the experiment without any significant difference between them. Interestingly, gradual reduction of food intake when accompanied with normal growth and weight gain is considered as the normal physiological dietary and growth behaviour for NZW rabbits [50]. These results indicated that the status of food intake in this experiment is consistent and homogeneous among all animals, and the supplemented food will not alter the outcome of this study.

Elevated biochemical liver parameters are considered as a diagnostic tool in the setting of NAFLD [51]. Elevated serum levels of ALT, AST, and other parameters of LFT are used as indicators for hepatocellular damage [52]. Alanine aminotransferase is more specific and preferred over AST in the diagnosis of liver injury [53]. Alanine aminotransferase is more related to pathology of liver fat [54]. This model of hypercholesterolemic rabbits appeared to be an ideal model for the study of NAFLD because it showed biochemical as well as the histopathological derangement of NAFLD/ NASH. This designed experiment is supported by Kainuma et al. [55] who reported that cholesterol-fed rabbits are useful models for the study of the pathophysiological aspects of NAFLD/NASH. In this model, the type of induced liver injury was a hepatocellular type. This is based on the results of the high cholesterol diet group that showed ALT serum level is $>2$ of the upper limit of normal (ULN) [56]. The criteria for identification of drug-induced liver injury have been modified to include the following: ALT $\geq 3$ ULN and total serum bilirubin $\geq 2$ ULN [53], which were also applicable to the current model.

In this experiment, feeding of rabbits with $1 \%$ cholesterol diet for 12 weeks resulted in a very extensive elevation of hepatic ALT and AST in the high cholesterol diet group when compared to the control groups. This is consistent with investigation conducted by Kim et al. [57] who reported altered liver enzymes after feeding the NZW rabbits with $1 \%$ cholesterol for 3 months. But the results of the present study are not consistent with Kainuma et al. [55] who reported the transaminases had not been changed in the NAFLD model. Even though, the diagnostic role of liver AST and ALT in the setting of NAFLD is debatable [58], but up to date, they are still considered among the diagnostic biochemical markers of NAFLD [3].

This investigation demonstrated the protective role of Trihoney against impaired liver function in NAFLD/NASH complex. Treatment groups received Trihoney expressed normal serum AST and ALT and were very comparable to the control groups. Trihoney seems to reduce liver transaminases in concurrent hypercholesterolemia in a dosedependent pattern.

Moreover, in this experiment, no significant difference was observed between all groups for serum ALP, GGT, and bilirubin, but treatment groups received Trihoney showed lower serum levels of these parameters in comparison to the high cholesterol diet group. Interestingly, the animal group which received Trihoney with normal diet expressed low serum levels of all hepatic biochemical markers (AST, ALT, GGT, ALP, and total bilirubin) in comparison to the control group that was maintained only on commercial diet. This may indicate the medical beneficial role of Trihoney even in normocholesterolemic status. These findings are supported by other animal studies investigating the hepatoprotective role of honey $[14,59,60]$.

Statins are recommended treatment option for NAFLD as the dyslipidemia controlling agent because $70 \%$ of patients with NAFLD was found to have dyslipidemia [61]. Use of statins in the management of NAFLD is strictly limited to certain criteria determined by the histopathological picture of NAFLD/NASH [1]. In a randomised clinical trial study investigating combination of atorvastatin with vitamins $C$ and $\mathrm{E}$ for 4-year duration in individuals with NAFLD, the results showed reduction in the risk of having moderate to 

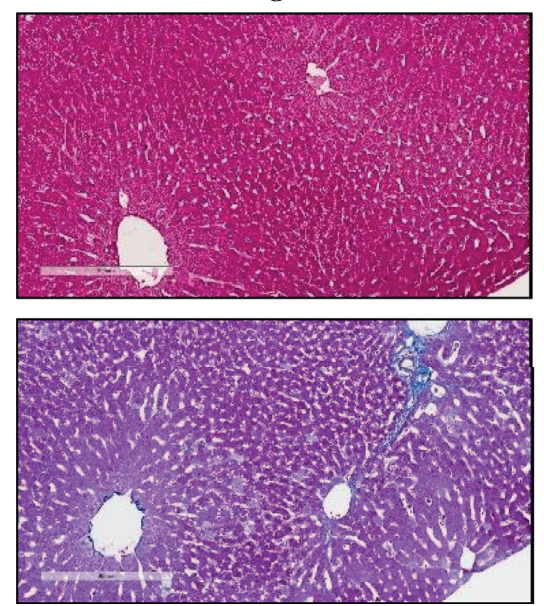

$\mathrm{HCD}+\mathrm{H}_{1}$
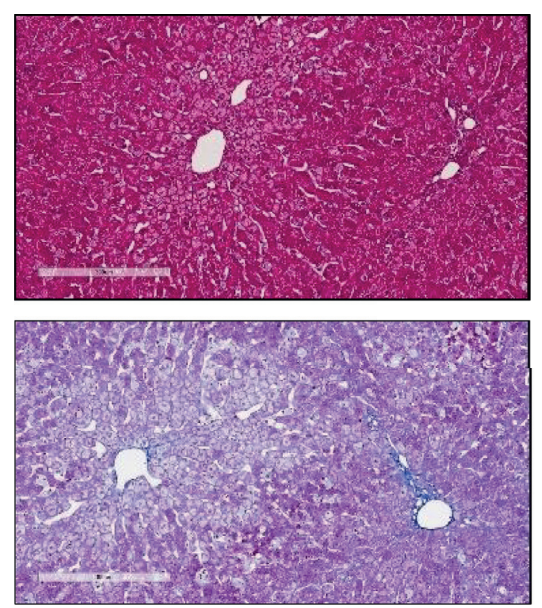

$\mathrm{C}+\mathrm{H}$
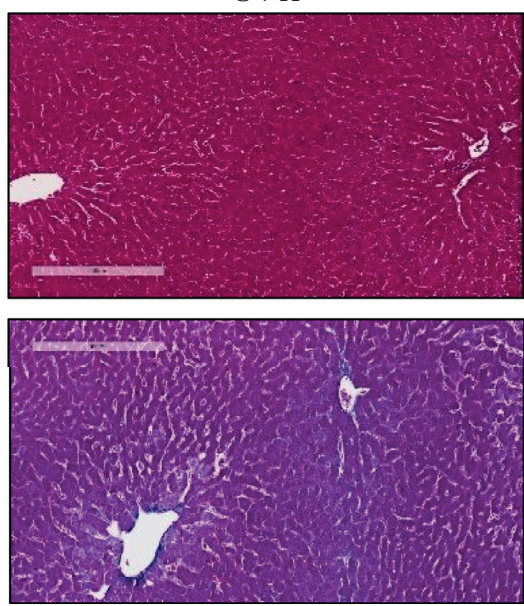

(a)

$\mathrm{HCD}+\mathrm{H}_{2}$
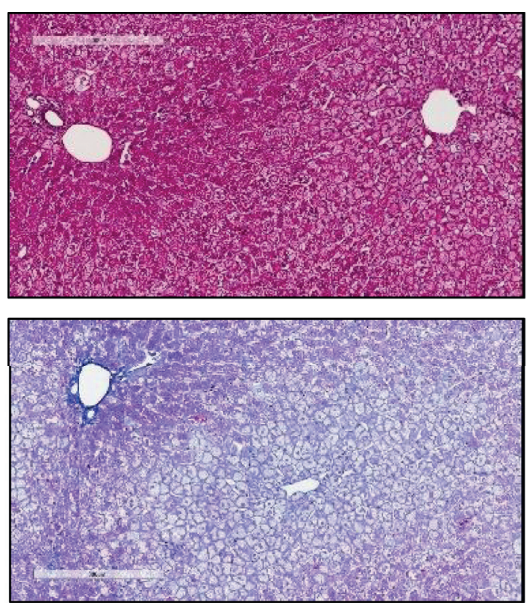

(b)
HCD
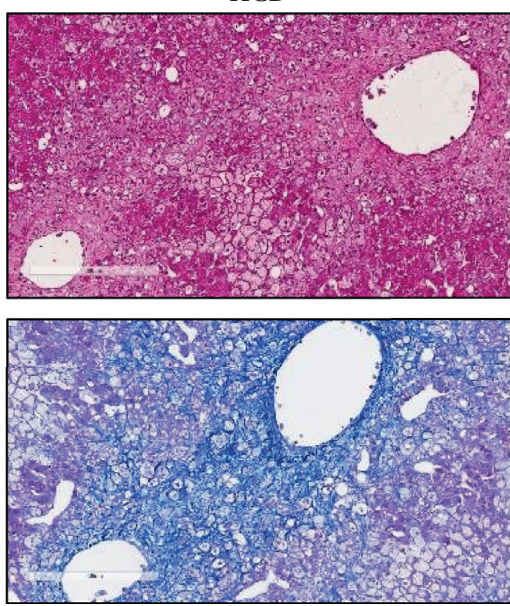

$\mathrm{HCD}+$ At.
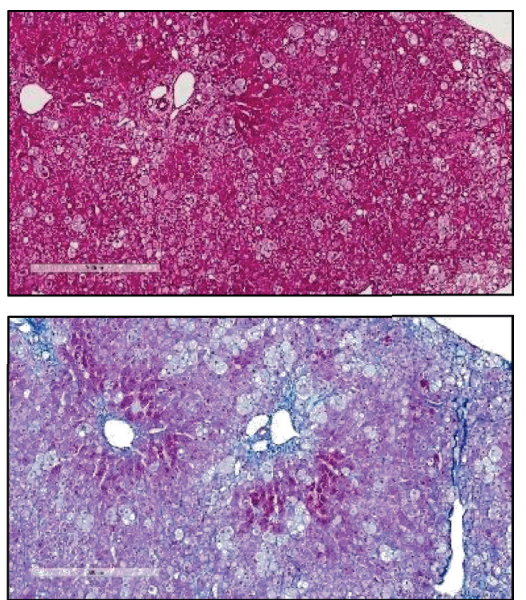

FiguRE 3: Microscopic features of a representative liver section from each experimental group: Haematoxylin and eosin stain (a); Masson's trichrome stain (b).

severe steatosis by $70 \%$ [61]. This may indicate synergistic effect can be obtained if atorvastatin is combined with natural antioxidants. In our experiment, supplementation of $2 \mathrm{mg} / \mathrm{kg} /$ day atorvastatin along with $1 \%$ cholesterol diet showed significant reduction in serum AST and ALT levels. These findings are consistent with prospective studies conducted on NAFLD and NASH patients having dyslipidemia in order to evaluate atorvastatin as treatment choice for NAFLD and NASH, and the authors reported the efficacy of atorvastatin in normalising transaminases serum levels $[62,63]$. In the current investigation, the atorvastatin-treated group expressed higher serum total bilirubin and GGT levels in comparison to other atherogenic groups even though elevation was statistically not significant but might indicate negative impact exerted by atorvastatin on NAFLD established disease. Elevated serum GGT is an indicator of hepatobiliary damage [64]. Safety and risk of statins in cases of liver diseases are still debatable. Atorvastatin reported in some cases to induce acute elevation of serum transaminases; however, it was transient and self-limiting in some cases and was severe hepatotoxicity in some others $[65,66]$. In a large cohort 4-year follow-up study, conducted by Chang et al. [67] on patients with chronic liver disease and being on statin treatment, the authors reported that atorvastatin in large doses can increase the risk of hospitalisation due to sever liver injury; otherwise, statins are still safe. The latest recommendations from United States Federal Drug Administration (US FDA) stated that statins are associated with very low risk of serious hepatic injury [68].

In this study, we reported evidence of oxidative stress by investigating MDA concentration in homogenate of the liver. In line with our study, elevated MDA in NAFLD/ NASH has been reported by various experimental as well as by clinical studies [69-74]. Pathophysiology of NAFLD is influenced by many environmental and genetic factors of which oxidative stress appeared as the main primary insult in starting and in progressing hepatic and extrahepatic damages [75]. In conjunction with high MDA concentrations, the HCD group had suppressed SOD and GPx activities in liver homogenate. In agreement with these 
findings, Xiao et al. [74] by in vitro and in vivo studies showed that, in status of NASH progression, the MDA production increased, while the protein expression of SOD and GPx suppressed. This is supported by Koruk et al. [76] who investigated oxidative stress in NASH patients, and the authors reported suppressed SOD along with elevated MDA in $\mathrm{NASH}$ subjects in comparison with healthy subjects. Interestingly, we reported significant results pertaining antioxidant potential of Trihoney. Supplementation of Trihoney resulted in a protective antioxidant effect expressed as enhancement of SOD and GPx activities in the liver despite presence of NAFLD/NASH. Concurrently, Trihoney supplementation exhibited significant ability to reduce lipid peroxidation and oxidative stress by suppression of MDA concentration in liver tissue. In agreement with our reported antioxidant-hepatoprotective results, Xiao et al. [74] showed that natural honey can alleviate hepatic oxidative stress by inhibition of MDA production and by reducing protein expression of both SOD and GPx enzymes. In line with our reports, natural honey was investigated by Kilicoglu et al. [15] for its role against obstructive jaundice-induced hepatic oxidative stress, and the authors concluded that natural honey expressed significant antioxidant function by suppression of hepatic MDA production in addition to histological protective effects. Natural honey exhibited antioxidant-hepatoprotective effects against aflatoxin-induced liver injury by restoration of MDA concentration and SOD activity to the normal range in the liver tissue which supports our results [60]. One of the underlying hepatoprotective mechanisms implicated in this setting is the inhibition of thioredoxin binding protein (TXNIP) overexpression. Thioredoxin binding protein is an important regulator for redox homeostasis, and reduction in its expression can suppress ROS production [77]. We may link the antioxidant to the anti-inflammatory effects of honey through TXNIP. Thioredoxin binding protein is found to be able to activate Nod-like receptor protein 3 (NLRP3) inflammasome which is implicated in inflammatory process and in progression of NASH. Xiao et al. [74] suggested that honey exerted its hepatoprotective effect by antioxidant and anti-inflammatory properties through inhibition of TXNIP, which subsequently suppresses NLRP3 inflammasome. The antioxidant potential of honey has been attributed in part to its polyphenolic contents [78]. Liu et al. [70] reported antioxidant effect of blue honeysuckle against NAFLD and attributed hepatoprotective effect to the blue honeysuckle polyphenolic contents. We may postulate that Trihoney has potential hepatoprotective effects against NAFLD/NASH through antioxidant function. Trihoney antioxidant effect may be attributed in part to its high phenolic contents for which it was formulated, in addition to other possible molecular mechanisms requiring future studies.

In this investigation, atherogenic group treated with atorvastatin expressed suppressed SOD and GPx activities in the liver coincidently with reduced lipid peroxidation manifested by low MDA concentration in hepatic tissue. Regarding hepatoprotective function of atorvastatin in this investigation, we found the following: reduced lipid peroxidation and normal biochemical liver function; these two effects may be consistent to indicate the role of atorvastatin in management of NAFLD, but simultaneously, we reported marked suppression of SOD and GPx activities in the liver in addition to the nonprotective histological effect; collectively, these results make the effects of atorvastatin in NAFLD inconsistent and nonconclusive and necessitate future research studies to further explain and resolve this issue. In line with this conclusion, Sigler et al. [79] showed evidence by a comprehensive review of a recent 12 clinical trials that statins are safe to be used in NAFLD patients, but their specific prescription for NAFLD treatment remained unclear due to controversy of liver histological outcomes. In accordance with our findings, Hyogo et al. [63] and GómezDomínguez et al. [80] reported that statins had significant reducing effect on MDA in addition to significant improvement in liver biochemical function, but the authors ignored antioxidant enzymes assay; additionally, they reported some patients had unexplained progression in liver fibrosis. In a randomised clinical trial investigated effect of combination of atorvastatin with vitamins $\mathrm{C}$ and $\mathrm{E}$ as antioxidants in NAFLD subjects, Foster et al. [61] showed significant reduction of liver steatosis in NAFLD subjects after 4 years of active therapy, but the study did not include antioxidant effect of atorvastatin. Such study encourages us to propose combination of Trihoney with atorvastatin as a therapeutic regimen for hyperlipidemic NAFLD patients. Such adjuvant therapy may protect against the unwanted histological side effects of atorvastatin, and the patients may get benefit of other pleiotropic functions of honey.

As far as histopathology of NAFLD is concerned, histopathological examination remained the cornerstone diagnostic tool for this disease [3]. In this study, we succeeded to induce NAFLD/NASH complex in NZW rabbits by feeding them $1 \%$ cholesterol diet for 12 weeks duration. Dyslipidemia and hypercholesterolemia are well-known leading causes to NAFLD [10, 81]. Our model of NAFLD may be considered as ideal for translational investigations because it showed the spectrum from steatosis to the fibrosis. The reported macroscopic examination of the liver in the current study showed difference between various groups, and the difference could be attributed to the impact of high cholesterol diet on the pathological process induced in the liver. Both HCD and HCD + At. groups showed similar gross findings. Our mentioned gross findings were in agreement with Xiaomin Wang et al. [82] who investigated NAFLDinduced high cholesterol diet. These gross findings were very consistent with the microscopic picture demonstrated by $\mathrm{H} \& \mathrm{E}$ and MT staining of liver tissues. These experimental groups had the full spectrum of NAFLD/NASH (steatosis, ballooning, inflammation, and hepatic fibrosis) in addition to presence of Mallory-Denk bodies in abundance, indicating the severity of NASH. According to Brunt et al. [48] grading and staging system of $\mathrm{NASH}$, these experimental groups fall in grade- 2 and fibrotic stage-3. The positive correlation between Mallory-Denk bodies and severity of steatosis and hepatitis was reported by Kayaçetin [83], which supports our histopathological description. In this study, use of atorvastatin showed no protective effect on histological picture of NAFLD in hypercholesterolemic rabbits, but 
serum transaminases maintained within normal and serum lipids (lipid profile not shown) significantly reduced; this is in line with Hyogo et al. [63], who reported normalisation of serum transaminases, while the histological picture of $\mathrm{NASH}$ improved in some patients and got worse in some others due to progression of fibrosis. Gómez-Domínguez et al. [80] reported the effectiveness of atorvastatin in lowering liver transaminases, but no effect is shown on liver fat contents, which support our results. Recently, Cioboată et al. [62] showed effectiveness of atorvastatin in normalising liver transaminases, but no impact was reported on hepatic fibrosis although they reported some reduction in steatosis. Our findings will add to the debate about use of statins in NASH patients. The debate and contradiction among experimental and clinical trials about the efficacy of hepatoprotective and therapeutic role of statins for NASH is still existing [1]. In clinical practice, it a very common to come across patients having hypercholesterolemia and cardiovascular diseases with concurrent NAFLD and NASH. In such cases, clinical practitioners have to decide about the use of statins, which represent an integral part of the regimen of such patients. In the current study, we used atorvastatin for this purpose and to add a knowledge about the safety of statins in status of hypercholesterolemic subjects having NAFLD or NASH. This aim was achieved by the current study, and it was supported by the literature. The current study indicated that, in subjects having hypercholesterolemia with NAFLD or NASH, the liver function should be monitored, and hepatic histology should be followed up for possibility of worsening of fibrosis.

On the contrary, macroscopic features of the liver in Trihoney-supplemented groups were in pale yellowish colour and had smooth surface, sharp edge, brown cut surface, and smooth consistency. These gross findings were in line with the microscopic histological features of these tissues. These groups had (mild) grade-1 NASH and fibrotic stage- 1 according to Brunt et al. [48] grading and staging system of NASH. In this study, we may assume that Trihoney had potential hepatoprotective effect against progression of NAFLD to NASH. To the best of our knowledge, this is the first study that used this novel Trihoney for testing its hepatoprotective potential in hypercholesterolemia-induced NAFLD. As far as hepatoprotective effect of honey is concerned, Erejuwa et al. [14] reported the hepatoprotective effect of Malaysian Tualang (dorsata) honey in a diabetic rat model, but the study was biochemical and not histopathological. Korkmaz and Kolankaya [84] used the rat model and mentioned the histological protective effect of Anzer honey (Turkish honey) against liver injury induced by $N$-ethylmaleimide. Hepatoprotective histological effect of natural honey was reported also by Yaman et al. [60] who investigated honey versus aflatoxin in the rat model. The authors of those studies attributed the hepatoprotective effect of honey to its antioxidant properties. In the rat model with induced NAFLD, honey was investigated for its ability to ameliorate the histopathological changes in $\mathrm{NASH}$, and the authors attributed the hepatoprotective effects of honey to its antioxidant and anti-inflammatory properties [74]. This is very consistent with our investigations. In a study on the rabbit model of NAFLD, the authors investigated flavonoid from grape and they reported a promising effect in minimising histological signs of NAFLD [85], and this supports our study in terms of role of natural flavonoids in protection against NAFLD. In a study using mice NAFLD model, the authors investigated the protective effect of blue honeysuckle extract against NAFLD; they characterised that extract as rich in polyphenols and showed hepatoprotective results against NAFLD, explored the antioxidant mechanism, and assigned it as the most likely underlying protective mechanism [70]. Likewise, Trihoney is a combination rich in phenolic compounds [16], and we may assume that the hepatoprotective effect of Trihoney may attribute to its antioxidant function. The exact molecular mechanisms need further studies. From our study, we can integrate both biochemical and histological effects of Trihoney as protective effects, but atorvastatin showed biochemical protective effect and no structural protective impact on liver tissue in NAFLD/NASH.

Since inflammation and oxidative stress secondary to hepatic lipid accumulation are implicated in the pathogenesis of NAFLD/NASH [6], and because the hepatoprotective functions of honey could be attributed to the antioxidant $[14,59]$ and to the anti-inflammatory [86] properties of honey, Trihoney could normalise the liver function and protect against progression of NAFLD to NASH through antioxidant and anti-inflammatory effects. Trihoney through the antioxidant study on liver homogenate in this work was proven to possess a tremendous antioxidant function through enhancement of hepatic antioxidant enzymes such as SOD and GPx. Moreover, Trihoney showed a very potent antioxidant effect against lipid peroxidation. Furthermore, Trihoney reported to have a systemic antioxidant effect and anti-inflammatory function against some inflammatory mediators implicated in the pathogenesis of NAFLD and NASH $[16,19]$. Concurrently, this experiment provided evidence of a strong positive correlation between hypercholesterolemia and transaminitis (elevated AST). We reported a lipid lowering effect of Trihoney in a previous work [87]; taking this in consideration, Trihoney may exert its hepatoprotective effect through hypocholesterolaemic, antioxidant, and anti-inflammatory mechanisms.

\section{Conclusion}

In a status of sustained hypercholesterolemia, Trihoney was an effective hepatoprotective supplement protecting against functional and structural changes in NAFLD. Trihoney was able to maintain liver biochemical parameters within the normal range and showed ameliorative potential against hepatic oxidative stress. Trihoney exhibited protective function against histological progression of NAFLD to NASH and restrains hepatic fibrosis. Trihoney may be introduced as an adjuvant therapy with atorvastatin for hypercholesterolemic NAFLD patients. Although this study showed the hepatoprotective functions of Trihoney against 
NAFLD, some underlying mechanisms at molecular and at immunohistopathological levels have not been addressed, which represents a limitation in this study. Future studies covering alpha-smooth muscle staining in addition to therapeutic experimental model assessment for Trihoney are highly recommended.

\section{Data Availability}

The data used to support the findings of this study are included within the article.

\section{Conflicts of Interest}

The authors declare that there are no conflicts of interest regarding the publication of this paper.

\section{Acknowledgments}

The authors would like to acknowledge the RMC-IIUM for providing the supporting grant of this research. The authors also thank the Libyan Programme for Reintegration and Development-Libya for sponsoring residency of the first author in Malaysia during research performance. This research was funded by the Fundamental Research Grant Scheme for Research Acculturation of Early Career Researchers (FRGS-RACER) (Grant nos. RACER19-012-0012) provided by Research Management Centre-International Islamic University Malaysia (RMCIIUM).

\section{References}

[1] Y. Sumida and M. Yoneda, "Current and future pharmacological therapies for NAFLD/NASH," Journal of Gastroenterology, vol. 53, no. 3, pp. 362-376, 2018.

[2] G. Musso, R. Gambino, and M. Cassader, "Non-alcoholic fatty liver disease from pathogenesis to management: an update," Obesity Reviews, vol. 11, no. 6, pp. 430-445, 2009.

[3] D. L. Dumitrascu and M. G. Neuman, "Non-alcoholic fatty liver disease: an update on diagnosis," Medicine and Pharmacy Reports, vol. 91, no. 2, pp. 147-150, 2018.

[4] Z. M. Younossi, A. B. Koenig, D. Abdelatif, Y. Fazel, L. Henry, and M. Wymer, "Global epidemiology of nonalcoholic fatty liver disease-meta-analytic assessment of prevalence, incidence, and outcomes," Hepatology, vol. 64, no. 1, pp. 73-84, 2016.

[5] J. G. Fan, S. U. Kim, and V. W. S. Wong, "New trends on obesity and NAFLD in Asia," Journal of Hepatology, vol. 67, no. 4, pp. 862-873, 2017.

[6] E. Buzzetti, M. Pinzani, and E. A. Tsochatzis, "The multiplehit pathogenesis of non-alcoholic fatty liver disease (NAFLD)," Metabolism, vol. 65, no. 8, pp. 1038-1048, 2016.

[7] K. Cusi, "Role of insulin resistance and lipotoxicity in nonalcoholic steatohepatitis," Clinics in Liver Disease, vol. 13, no. 4, pp. 545-563, 2009.

[8] I. A. Kirpich, L. S. Marsano, and C. J. McClain, "Gut-liver axis, nutrition, and non-alcoholic fatty liver disease," Clinical Biochemistry, vol. 48, no. 13-14, pp. 923-930, 2015.

[9] X. Xu, L. Lu, Q. Dong et al., "Research advances in the relationship between nonalcoholic fatty liver disease and atherosclerosis," Lipids in Health and Disease, vol. 14, no. 1, pp. 1-8, 2015.

[10] D. Jahn, S. Kircher, H. M. Hermanns, and A. Geier, "Animal models of NAFLD from a hepatologist's point of view," Molecular Basis of Disease, vol. 5, pp. 1-35, 2018.

[11] F. Sofi and A. Casini, "Mediterranean diet and non-alcoholic fatty liver disease: New therapeutic option around the corner?" World Journal of Gastroenterology, vol. 20, no. 23, pp. 7339-7346, 2014.

[12] A. Ajibola, J. P. Chamunorwa, and K. H. Erlwanger, "Nutraceutical values of natural honey and its contribution to human health and wealth," Nutrition and Metabolism, vol. 9, pp. 1-12, 2012.

[13] N. S. Al-Waili, K. Y. Saloom, T. N. Al-Waili et al., "Influence of various diet regimens on deterioration of hepatic function and hematological parameters following carbon tetrachloride: a potential protective role of natural honey," Natural Product Research, vol. 20, no. 13, pp. 1258-1264, 2006.

[14] O. O. Erejuwa, S. A. Sulaiman, M. S. Wahab, K. N. S. Sirajudeen, M. S. Salleh, and S. Gurtu, "Hepatoprotective effect of tualang honey supplementation in streptozotocin-induced diabetic rats," International Journal of Applied Research in Natural Products, vol. 4, no. 4, pp. 37-41, 2012.

[15] B. Kilicoglu, C. Gencay, K. Kismet et al., "The ultrastructural research of liver in experimental obstructive jaundice and effect of honey," American Journal of Surgery, vol. 195, no. 2, pp. 249-256, 2008.

[16] H. A. H. Alfarisi, M. Ibrahim, Z. B. H. Mohamed, A. H. Hamdan, and C. A. Che Mohamad, "Trihoney suppresses soluble adhesion molecules ( ICAM-1 and VCAM-1 ) in hypercholesterolemic atherosclerotic rabbits: a comparative study with atorvastatin," Sains Malaysiana, vol. 49, no. 6, pp. 1313-1322, 2020.

[17] S. Peng, N. Ling, Y. Aniza, S. Wei, and L. Suan, "Total phenolic contents and colour intensity of Malaysian honeys from the Apis spp. and Trigona spp." Bees Agriculture and Agricultural Science Procedia, vol. 2, pp. 150-155, 2014.

[18] M. I. Khalil, N. Alam, M. Moniruzzaman, S. A. Sulaiman, and S. H. Gan, "Phenolic acid composition and antioxidant properties of Malaysian honeys," Journal of Food Science, vol. 76, no. 6, pp. C921-C928, 2011.

[19] H. A. H. Alfarisi, M. Ibrahim, Z. B. H. Mohamed, A. H. Hamdan, and C. A. Che Mohamad, "Trihoney reduces lipid peroxidation and enhances antioxidant enzyme activities in hypercholesterolaemic atherosclerotic rabbits," International Food Research Journal, vol. 27, no. 3, pp. 568-575, 2020.

[20] M. Mahaneem, S. A. Sulaiman, H. Jaafar et al., "Effect of honey on testicular functions in rats exposed to cigarette smoke," Journal of ApiProduct and ApiMedical Science, vol. 3, no. 1, pp. 12-17, 2011.

[21] Natural Medicines Comprehensive Database, Therapeutic Research Faculty, Publishers Of Natural Medicines Comprehensive Database, Prescriber's Letter, And Pharmacist's Letter, Natural Medicines Comprehensive Database, University of Florida, Gainesville, FL, USA, 2016.

[22] S. Reagan-Shaw, M. Nihal, and N. Ahmad, "Dose translation from animal to human studies revisited," The FASEB Journal, vol. 22, no. 3, pp. 659-661, 2007.

[23] B. Du, G. Xu, H. Cao et al., "Effects of atorvastatin on expression of ICAM-1 in atherosclerotic rabbits," Journal of Cardiovascular Medicine, vol. 14, no. 2, pp. 120-126, 2013.

[24] P. A. R. Jorge, E. A. D. Almeida, M. Ozaki, and A. Carneiro, "Efeitos da atorvastatina, fluvastatina, pravastatina e 
simvastatina sobre a função endotelial, a peroxidação lipídica e a aterosclerose aórtica em coelhos hipercolesterolêmicos," Arquivos Brasileiros de Cardiologia, vol. 84, no. 4, pp. 314-319, 2005.

[25] X. Song, H. Liu, X. Wang, Z. Li, and C. Huang, "Atorvastatin combined with poly-unsaturated fatty acid confers better improvement of dyslipidemia and endothelium function," Lipids in Health and Disease, vol. 13, no. 1, pp. 1-5, 2014.

[26] F. Luo, Y. Guo, G. Y. Ruan et al., "Combined use of metformin and atorvastatin attenuates atherosclerosis in rabbits fed a high-cholesterol diet," Scientific Reports, vol. 7, no. 1, pp. 1-10, 2017.

[27] AEPC, Animal Ethics Policy, International Islamic University, Kuantan, Malaysia, 2012.

[28] R. J. Torres, A. de, L. de Noronha et al., "Increased intercellular adhesion molecule-1 immunoreactivity in the sclerachoroid complex in hypercholesterolemia experimental model," Revista Brasileira de Oftalmologia, vol. 73, no. 4, pp. 210-215, 2014.

[29] I. M. Bolayirli, M. Aslan, H. Balci, T. Altug, M. Hacibekiroglu, and A. Seven, "Effects of atorvastatin therapy on hypercholesterolemic rabbits with respect to oxidative stress, nitric oxide pathway and homocysteine," Life Sciences, vol. 81, no. 2, pp. 121-127, 2007.

[30] J. Fan, H. Shimoyamada, H. Sun, S. Marcovina, K. Honda, and T. Watanabe, "Transgenic rabbits expressing human apolipoprotein(a) develop more extensive atherosclerotic lesions in response to a cholesterol-rich diet," Arteriosclerosis, Thrombosis, and Vascular Biology, vol. 21, no. 1, pp. 88-94, 2001.

[31] J. Gourdon, Large animal euthanasia, McGill University, Montréal, Québec, Canada.

[32] S. Mohanta, C. Yin, C. Weber, D. Hu, and A. Habenicht, "Aorta atherosclerosis lesion analysis in hyperlipidemic mice," Bio-Protocol, vol. 6, no. 11, pp. 1-15, 2016.

[33] M. Alegret, J. C. Verd, C. Díaz et al., "Effect of hypolipidemic drugs on key enzyme activities related to lipid metabolism in normolipidemic rabbits," European Journal of Pharmacology, vol. 347 , no. 2-3, pp. 283-291, 1998.

[34] G. A. Otunola, O. B. Oloyede, A. T. Oladiji, and A. A. Afolayan, "Effects of diet-induced hypercholesterolemia on the lipid profile and some enzyme activities in female Wistar rats," African Journal of Biochemistry Research, vol. 4, no. 6, pp. 149-154, 2010.

[35] G. Morawietz, C. Ruehl-Fehlert, B. Kittel et al., "Revised guides for organ sampling and trimming in rats and mice Part 3," Experimental and Toxicologic Pathology, vol. 55, no. 6, pp. 433-449, 2004.

[36] R. Hellmann, K. Sakata, T. Kunieda, S. Saji, H. Doi, and Y. Nozawa, "Quantitative evaluation of fatty liver by computed tomography in rabbits," American Journal of Roentgenology, vol. 142, no. 4, pp. 741-746, 1984.

[37] T. T. Wissniowski, J. Hänsler, and D. Neureiter, "Activation of tumor-specific $\mathrm{T}$ lymphocytes by radio-frequency ablation of the VX2 hepatoma in rabbits," Cancer Research, vol. 63, no. 19, pp. 6496-6500, 2003.

[38] S. Hünsler, "Taking blood sample from rabbit," IDEXX Laboratory, pp. 1-11, 2016.

[39] C. T. Chang, P. Y. Lee, and W. L. Cheah, "The prevalence of cardiovascular risk factors in the young and middle-aged rural population in Sarawak, Malaysia," The Malaysian Journal of Medical Sciences, vol. 19, no. 2, pp. 27-34, 2012.

[40] S. Sukardi, H. Yaakub, S. Ganabadi, and P. Ms, "Serum testosterone levels and body weight gain of male rabbits fed with Morinda citrifolia fruit juice," Malaysian Journal of Nutrition, vol. 11, no. 1, pp. 59-68, 2005.

[41] M. Ibrahim, I. A. Ahmed, M. A. Mikail et al., "Baccaurea angulata fruit juice reduces atherosclerotic lesions in dietinduced Hypercholesterolemic rabbits," Lipids in Health and Disease, vol. 16, no. 1, pp. 1-8, 2017.

[42] S. A. Noeman, H. E. Hamooda, and A. A. Baalash, "Biochemical study of oxidative stress markers in the liver, kidney and heart of high fat diet induced obesity in rats," Diabetology \& Metabolic Syndrome, vol. 3(1), no. 17, 2011.

[43] R. Badalzadeh, N. Layeghzadeh, A. Alihemmati, and M. Mohammadi, "Beneficial effect of troxerutin on diabetesinduced vascular damages in rat aorta: histopathological alterations and antioxidation mechanism," International Journal of Endocrinology and Metabolism, vol. 13, no. 2, 2015.

[44] M. E. Soto, E. Soria-Castro, V. Levy et al., "analysis of oxidative stress enzymes and structural and functional proteins on human aortic tissue from different aortopathies," Oxidative Medicine and Cellular Longevity, vol. 2014, pp. 1-13, 2014.

[45] W. T. Guarner Lans, R. I. Levy, and D. S. Fredrickson, "Estimation of the concentration of low-density lipoprotein cholesterol in plasma, without use of the preparative ultracentrifuge," Clinical Chemistry, vol. 18, no. 6, pp. 499-502, 1972.

[46] B. Wang, R.-N. Yang, Y.-R. Zhu et al., "Involvement of xanthine oxidase and paraoxonase 1 in the process of oxidative stress in nonalcoholic fatty liver disease," Molecular Medicine Reports, vol. 15, no. 1, pp. 387-395, 2016.

[47] M. Qiu, "Role of special stains in diagnostic liver pathology," Clinical Liver Disease, vol. 2, no. SUPPL. 1, pp. 8-10, 2013.

[48] E. M. Brunt, C. G. Janney, A. M. Bisceglie, B. A. Neuschwander-Tetri, B. R. Bacon, and B. R. Bacon, "Nonalcoholic steatohepatitis: a proposal for grading and staging the histological lesions," The American Journal of Gastroenterology, vol. 94, no. 9, pp. 2467-2474, 1999.

[49] ARRP, Guidelines for the Housing of Rabbits in Scientific Institutions, ARRP, Sydney, Australia, 2003.

[50] F. Lebas, P. Coudert, H. De Rochambeau, R. G. Thebault, R. Rouvier, and H. De Rochambeau, "The rabbit: husbandry, health and production," The Rabbit, vol. 121, 1997.

[51] P. Maharjan, P. Khanal, N. P. Parajuli, G. Joshi, and H. Parajuli, "Biochemical changes in non-alcoholic fatty liver disease ( NAFLD ): a study in nepalese population," Annals of Clinical Biochemistry, vol. 2, no. 2, pp. 15-20, 2016.

[52] P. Coates, "Liver function tests," Australian Family Physician, vol. 40, no. 3, pp. 113-115, 2011.

[53] Y. Liu, Y. Ding, J. Wang et al., "CSH guidelines for the diagnosis and treatment of drug-induced liver injury," Hepatology International, vol. 11, no. 3, pp. 221-241, 2017.

[54] S. Saligram, E. Williams, and M. Masding, "Raised liver enzymes in newly diagnosed Type 2 diabetes are associated with weight and lipids, but not glycaemic control," Indian Journal of Endocrinology and Metabolism, vol. 16, no. 6, pp. 10121015, 2012.

[55] M. Kainuma, M. Fujimoto, N. Sekiya et al., "Cholesterol-fed rabbit as a unique model of nonalcoholic, nonobese, noninsulin-resistant fatty liver disease with characteristic fibrosis," Journal of Gastroenterology, vol. 41, no. 10, pp. 971-980, 2006.

[56] C. Shimada, "Criteria of drug-induced liver disorders," Journal of Hepatology, vol. 11, no. 2, pp. 272-276, 1990.

[57] E. J. Kim, B. H. Kim, H. S. Seo et al., "Cholesterol-induced non-alcoholic fatty liver disease and atherosclerosis 
aggravated by systemic inflammation," PLoS One, vol. 9, no. 6, pp. 1-11, 2014.

[58] G. C. Farrell and J. George, "Practical approach to the diagnosis and management of people with fatty liver diseases," Fatty Liver Disease: NASH and Related Disorders, pp. 181-193, Blackwell Publishing Ltd., Hoboken, NJ, USA, 2005.

[59] M. Kassim, M. Mansor, N. Al-abd, and K. M. Yusoff, "Gelam honey has a protective effect against lipopolysaccharide (LPS)Induced organ failure," International Journal of Molecular Sciences, vol. 13, no. 5, pp. 6370-6381, 2012.

[60] T. Yaman, Z. Yener, and I. Celik, "Histopathological and biochemical investigations of protective role of honey in rats with experimental aflatoxicosis," Complementary and Alternative Medicine, vol. 16, no. 1, pp. 1-11, 2016.

[61] T. Foster, M. J. Budoff, S. Saab, N. Ahmadi, C. Gordon, and A. D. Guerci, "Atorvastatin and antioxidants for the treatment of nonalcoholic fatty liver disease: the st francis heart study randomized clinical trial," American Journal of Gastroenterology, vol. 106, no. 1, pp. 71-77, 2011.

[62] R. Cioboată, A. Găman, D. Traşcă et al., "Pharmacological management of non-alcoholic fatty liver disease: atorvastatin versus pentoxifylline," Experimental and Therapeutic Medicine, vol. 13, no. 5, pp. 2375-2381, 2017.

[63] H. Călina, S. Tazuma, K. Arihiro et al., "of atorvastatin for the treatment of nonalcoholic steatohepatitis with dyslipidemia," Metabolism, vol. 57, no. 12, pp. 1711-1718, 2008.

[64] F. Ishitobi, "North american veterinary," in Understanding Clinical Pathology in Rabbits, M. J. Murray, Ed., in Proceedings of the North American Veterinary Conference, vol. 20, pp. 1751-1753, 2006.

[65] S. Thotakura, A. Singh, K. Khera, S. Chauhan, and T. Devasia, "Atorvastatin-induced hepatotoxicity, increased by clopidogrel stress on CYP450 enzyme: understanding the mechanism through a case," Journal of Applied Pharmaceutical Science, vol. 8, no. 4, pp. 168-170, 2018.

[66] Y. Liu, Z. Cheng, L. Ding et al., “Atorvastatin-induced acute elevation of hepatic enzymes and the absence of cross-toxicity of pravastatin," Int. Journal of Clinical Pharmacology and Therapeutics, vol. 48, no. 12, pp. 798-802, 2010.

[67] C.-H. Shi, Y.-C. Chang, Y.-C. Lee et al., "Severe hepatic injury associated with different statins in patients with chronic liver disease: a nationwide population-based cohort study," Journal of Gastroenterology and Hepatology, vol. 30, no. 1, pp. 155$162,2015$.

[68] J. Lin, F. A. A. Al-tamimi, M. M. Helal, B. Jimmy, Q. Al Riyami, and J. Jose, "Statin associated hepatic adverse effects: a retrospective review from a regional hospital in sultanate of Oman," Oman Medical Journal, vol. 29, no. 5, pp. 351-357, 2014.

[69] N. Chalasani, M. A. Deeg, and D. W. Crabb, "Systemic levels of lipid peroxidation and its metabolic and dietary correlates in patients with nonalcoholic steatohepatitis," The American Journal of Gastroenterology, vol. 99, no. 8, pp. 1497-1502, 2004.

[70] M. Liu, J. Tan, Z. He et al., "Inhibitory effect of blue honeysuckle extract on high-fat-diet-induced fatty liver in mice," Animal Nutrition, vol. 4, no. 3, pp. 288-293, 2018.

[71] V. O. Palmieri, I. Grattagliano, P. Portincasa, and G. Palasciano, "Systemic oxidative alterations are associated with visceral adiposity and liver steatosis in patients with metabolic syndrome," The Journal of Nutrition, vol. 136, no. 12, pp. 3022-3026, 2006.

[72] N. Sharifi, R. Amani, E. Hajiani, and B. Cheraghian, "Does vitamin $\mathrm{D}$ improve liver enzymes, oxidative stress, and inflammatory biomarkers in adults with non-alcoholic fatty liver disease? a randomized clinical trial," Endocrine, vol. 47, no. 1, pp. 1-11, 2014.

[73] P. Stiuso, I. Scognamiglio, M. Murolo et al., "Serum oxidative stress markers and lipidomic profile to detect NASH patients responsive to an antioxidant treatment: a pilot study," Oxidative Medicine and Cellular Longevity, vol. 2014, Article ID 169216, 8 pages, 2014.

[74] J. Xiao, Y. Liu, F. Xing, T. M. Leung, E. C. Liong, and G. L. Tipoe, "Bee's honey attenuates non-alcoholic steatohepatitis-induced hepatic injury through the regulation of thioredoxin-interacting protein-NLRP3 inflammasome pathway," European Journal of Nutrition, vol. 55, no. 4, pp. 1465-1477, 2016.

[75] M. Masarone, V. Rosato, M. Dallio et al., "Role of oxidative stress in pathophysiology of nonalcoholic fatty liver disease," Oxidative Medicine and Cellular Longevity, vol. 2018, Article ID 9547613, 14 pages, 2018.

[76] M. Koruk, S. Taysi, M. C. Savas, O. Yilmaz, F. Akcay, and M. Karakok, "Oxidative stress enzymatic antioxidant status in patients with nonalcoholic steatohepatitis," Annals of Clinical and Laboratory Science, vol. 34, no. 1, pp. 57-62, 2004.

[77] J. Zhou and W. J. Chng, "Roles of thioredoxin binding protein (TXNIP) in oxidative stress, apoptosis and cancer," Mitochondrion, vol. 13, no. 3, pp. 163-169, 2013.

[78] H. T. L. Nguyen, N. Panyoyai, S. Kasapis, E. Pang, and N. Mantri, "Honey and its role in relieving multiple facets of atherosclerosis," Nutrients, vol. 11, no. 1, pp. 1-22, 2019.

[79] M. A. Sigler, L. Congdon, and K. L. Edwards, "An evidencebased review of statin use in patients with nonalcoholic fatty liver disease," Clinical Medicine Insights: Gastroenterology, vol. 11, pp. 1-9, 2018.

[80] E. Gómez-Domínguez, J. P. Gisbert, J. A. Moreno-Monteagudo, L. García-Buey, and R. Moreno-Otero, "A pilot study of atorvastatin treatment in dyslipemid, non-alcoholic fatty liver patients," Alimentary Pharmacology and Therapeutics, vol. 23, no. 11, pp. 1643-1647, 2006.

[81] N. Chalasani, Z. Younossi, J. E. Lavine et al., "The diagnosis and management of non-alcoholic fatty liver disease: practice guideline by the American association for the study of liver diseases, American college of gastroenterology, and the American gastroenterological association," Hepatology, vol. 55, no. 6, pp. 2005-2023, 2012.

[82] X. Sanyal, X. Zhang, L. Ma, and S. Li, "Simultaneous quantification of hepatic MRI-PDFF and R2* in a rabbit model with nonalcoholic fatty liver disease," Science China Life Sciences, vol. 61, no. 9, pp. 1107-1114, 2018.

[83] S. Kayaçetin and M. Basaranoglu, "Mallory-Denk bodies: correlation with steatosis, severity, zonal distribution, and identification with ubiquitin," The Turkish Journal of Gastroenterology, vol. 26, no. 6, pp. 506-510, 2015.

[84] A. Korkmaz and D. Kolankaya, "Anzer honey prevents $\mathrm{N}$-ethylmaleimide-induced liver damage in rats," Experimental and Toxicologic Pathology, vol. 61, no. 4, pp. 333-337, 2009.

[85] R. Franklin, R. F. M. Bispo, C. F. Sousa-Rodrigues, L. A. S. Pires, A. Fonseca, and M. A. Babinski, "Grape leucoanthocyanidin protects liver tissue in albino rabbits with nonalcoholic hepatic steatosis," Cells Tissues Organs, vol. 205, no. 3, pp. 129-136, 2018.

[86] N. Vallianou, "Honey and its anti-inflammatory, anti-bacterial and anti-oxidant properties," General Medicine: Open Access, vol. 2, no. 2, 2014. 
[87] H. A. H. Alfarisi, M. Ibrahim, N. Azahari, Z. B. H. Mohamed, and A. H. B Hamdan, "Anti-inflammatory effects of Trihoney in hypercholesterolemic atherosclerotic rabbits: a comparative study with atorvastatin," Malaysian Journal of Medicine and Health Sciences, vol. 16, no. 2, pp. 230-236, 2020. 